\title{
The Ability of Sustainable Development Research Based on Statistics Synthetic Appraisal Theory
}

\author{
Haiyi Sun ${ }^{1, a}$, Ning $\mathrm{Li}^{2, b^{*}}$, Jinbao Wang ${ }^{1, c}$ and Hongmei Yan ${ }^{1, d}$ \\ ${ }^{1}$ College of Science, Shenyang Jianzhu University, Shenyang, China \\ ${ }^{2}$ Colleges of Sciences, Northeastern University, Shenyang, China \\ âshy_xx@163.com, lining80@163.com, jinbao_wang@163.com, yan1204shanyu@163.com
}

Keywords: Sustainable development; Statistics synthetic; The Principal Component Analysis (PCA); Analytic Hierarchy Process (AHP); Cluster analysis

\begin{abstract}
In this paper, we make mathematical modeling and analysis on the sustainable development. In order to assess countries with different degree of sustainable development, we adapt the Principal Component Analysis (PCA) to collect a dozen factors which may affect the sustainable development for data analysis. For example, we filter 11 sets of data from 1990 to 2014 in the United States. Then we use the factor of principal component analysis to decide the solution layer of Analytic Hierarchy Process (AHP) and the rule layer. Our purpose is to use the specific value and weight of United States (11 factors* 25 years) dates to get calculation formula of level indicators of sustainable development. Then we calculate level indicators of 14 countries with different degree of the sustainable development, and use these data for clustering analysis. At last, we get five clustering center, we divide the sustainable development indicators into five kinds of indicators: unsustainable, low level middle level, good level and very good level of sustainability. Therefore, according to the levels of these indicators and classification, we have distinguished more sustainable countries from less sustainable ones.
\end{abstract}

\section{Introduction}

Since the 1960s, the idea of sustainable development is deeply rooted in our hearts and accepted by more and more human beings and countries. It is not only the important way to reduce the financial burden of the earth, but also a pillar of national stability. Monetary international conglomerate (ICM) requires us to create a more sustainable development for a country's future [1-5].

Currently influential representative index system is the United Nations commission on sustainable development (LTNCSD) 1996 a state response (PSR) help to pressure as the basic framework of indicator system, environment Canada-economic roundtable (NRTEE) 1995 index system based on response action one cycle, the 1996 sustainable development index system is put forward, the United States in 1996, put forward the index system of sustainable development, and based on the complex ecosystem theory, system dynamics theory and multi-objective decision technology and environmental economic system coordination degree model theory to construct the evaluation index system of sustainable development, etc [6-10].

In this paper, the main task of our paper is to establish an evaluation model on whether the country is sustainable or not, and put forward the reasonable measures of the sustainable development for the LDC countries. In the second section, we establish the assumptions that will be used in the rest of this article. The weights of criteria level factor can be obtain by Principal component analysis. In the third section, we set up the sustainable development model using the Analytic Hierarchy Process to assess whether a country is sustainable or not. In the fourth quarter, based on the two models at the front, we introduce the method of cluster analysis. According to cluster analysis, we analyze the sustainable level of the 14 countries. In the fifth section, we make the rationality analysis on our model and the promotion of the model. 


\section{The Analysis of Criteria Level Factor Weights}

\section{Assumption}

- The elements that we already have taken into consideration play a vital role in the evaluation.

- These factors that we ignored have little influence on the level of the sustainable development.

- The data that we have collected is enough and accurate for determining the sustainable level and the quantification are correct.

- The advice we put forward will has great influence on improving the level of the sustainable development.

The Obtainment of the Criteria Level Factor Weights. The weights of criteria level factor can be easily found on the Internet. Where in consideration of the weights of secondary critical level factor are too complex and unsure to observe visually, the Principal Component Analysis is established to determine that.

We give the Environment subsystem firstly. We find that there are several factors by looking for information and caring on the data collection. And these factors have an influence on the environment subsystem. Based on the principal component analysis, we analyze the data and all factors. The answer we gain is the Fig. 1.

The above results show that carbon dioxide emissions is exponentially smaller than the component matrix of marine protected area forestry area and the water resources of rural improvement which means it can be neglected in the following steps .

Based on the principal component analysis, we analyze the data and all factors. The answer we gain is the Fig. 2.

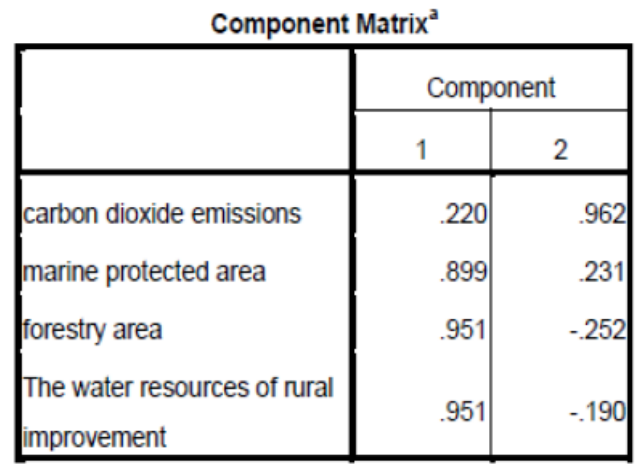

Extraction Method: Principal Component Analysis.

a. 2 components extracted.

Figure 1. Environment-The principal component factor

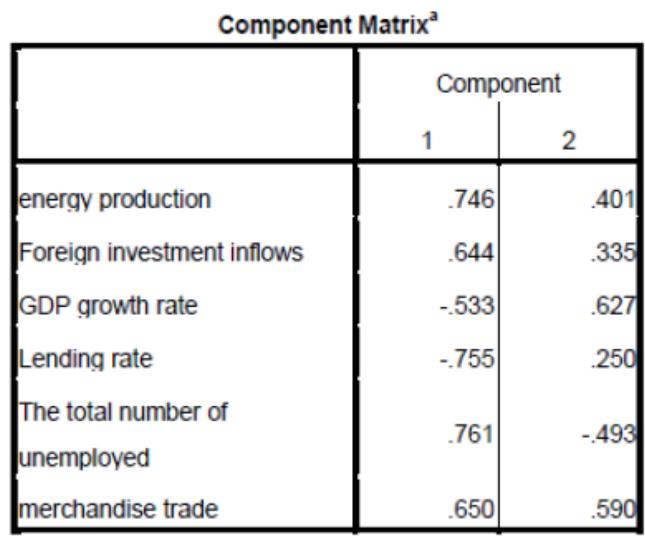

Extraction Method: Principal Component Analysis

a. 2 components extracted.

Figure 2. Economy-The principal component factor

This verifies that GDP growth rate is highly insensitive to the sustainable development, which means it can be neglected in the following steps.

Based on the principal component analysis, we analyze the data and all factors. The answer we gain is the following (i.e. Fig. 1.).

The above results show that the component matrix of female population percentage and the amount of unemployed people are less important than other factors, which means we can ignore it as our research object in the following steps.

In some situations, we must favor one over the other. According to the criterion of PCA, we ignore some little impact factors to simplified model. As a result, we have processed and simplified the data we collect. Our data will be used in the Fig. 3. 


\section{Establishment of the Evaluation System}

In this section, we set up the sustainable development model using the Analytic Hierarchy Process to assess whether a country is sustainable or not.

As we known, sustainable development can be divided into many aspects. However, in order to evaluate the level of sustainable development, based on the date we collect, the sustainable development level can be divided into the three systems of the environment, economy and society. We further classify this subsystem into several components. The three hierarchy structure contains criteria level and the alternatives level is in Fig. 4.

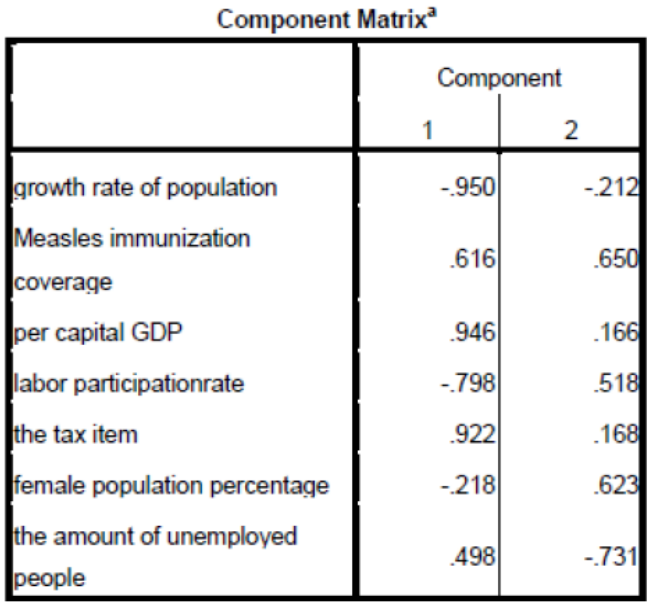

Extraction Method: Principal Component Analysis.

a. 2 components extracted

Figure 3. Social-The principal component factor

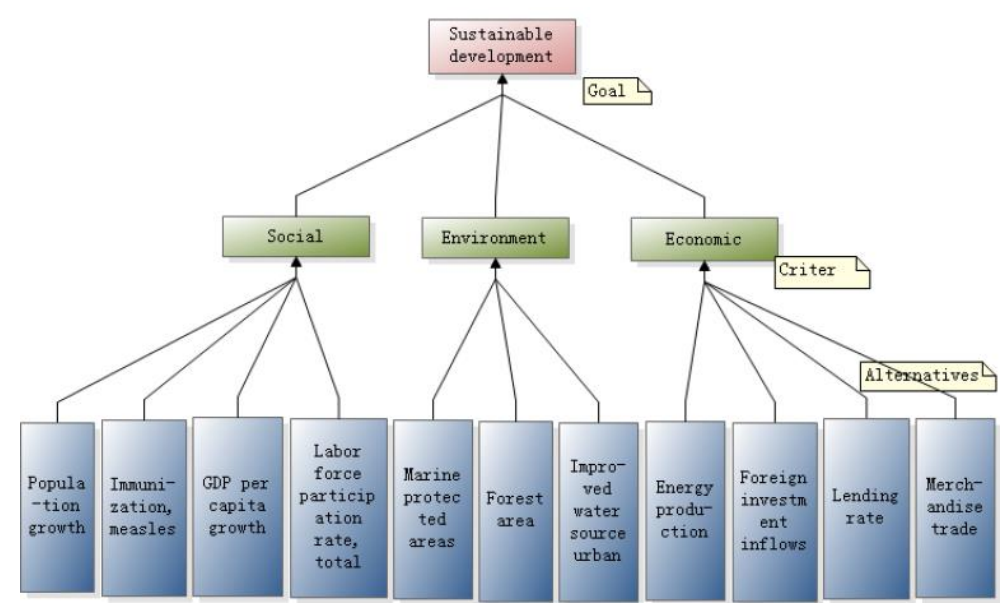

Figure 4. The flow chat of Hierarchical analysis

The Three-hierarchy Structure. We will decompose the decision problem into three levels, the top one is the goal layer, in this case, the sustainable development level. The bottom one is the Alternatives; there are a number of options. The middle layer is the criterion layer; we call it as environment, society and economy, respectively. The connection relationship between each layer is shown in the Fig. 4.

Obtain the Index Weight. The weights of criteria level factor can be easily found on the Internet. Consideration the weights of secondary critical level factor are too complex and unsure to be observed visually, the Principal Component Analysis is established to determine that. By using the internet, we obtain the weights of the middle layer, shown in the Fig.5. Therefore, the influence factors of the environment are bigger than that of the society and economy. And the influence of the development of the society is at very low degree on the sustainable development level. However, we think the sustainable development level of human in the period of primitive society is high; it is obvious that this is unrealistic.

According to the principal component analysis, we gain the weight, which is shown in the Fig. 6, as the important basis of judgment. According to the one-nine method, we gain the weight of the plan layer, shown in this figure.

Does the Consistency Check? $W_{i}$ Denotes the weight of $i^{\text {th }}$ criteria level factor, where $W_{j}$ is the weight of $j^{\text {th }}$ secondary critical level factor, and $F_{j}$ denotes the $j^{\text {th }}$ secondary critical level factor. The evaluation grade $Y_{1}$ should be

$$
L=\sum_{j=1}^{3} a W_{i} *\left[\sum_{j}^{m i}\left(b W_{j} * F_{j}\right)\right]
$$


- Judging \& matrix

$$
L=\left(\begin{array}{ccc}
1 & 1 / 7 & 1 / 5 \\
7 & 1 & 3 \\
5 & 1 / 3 & 1
\end{array}\right)
$$

- Weight vector of criteria level

$$
a W=\left[\begin{array}{lll}
0.0882 & 0.6687 & 0.2431
\end{array}\right]
$$

For this level, the indicator of consistency check $C I=0.0035$. The expression of consistency ratio $C R=0.0068$.Satisfying

$$
\frac{C I}{R I}<0.1
$$

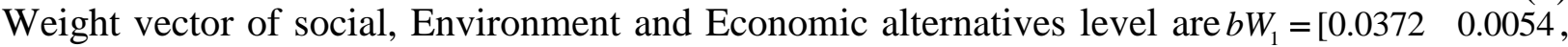
$0.03090 .0147], b W_{2}=\left[\begin{array}{llll}0.0493 & 0.4302 & 0.1892\end{array}\right], b W_{3}=\left[\begin{array}{llll}0.0816 & 0.0124 & 0.0232 & 0.1259\end{array}\right]$

All of these eight vectors satisfy $C I / R I<0.1$. Finally, we can obtain the final Levels of the Sustainable development using AHP models.

So far, based on the section II and section III we build, we obtained the important influencing factors and their weights of the sustainable development level by using the data of America in the past 26 years. By using the formula (1), we calculate the sustainability level of fourteen countries, these country including developed, developing, less developed countries, which is the preparation for the next model.

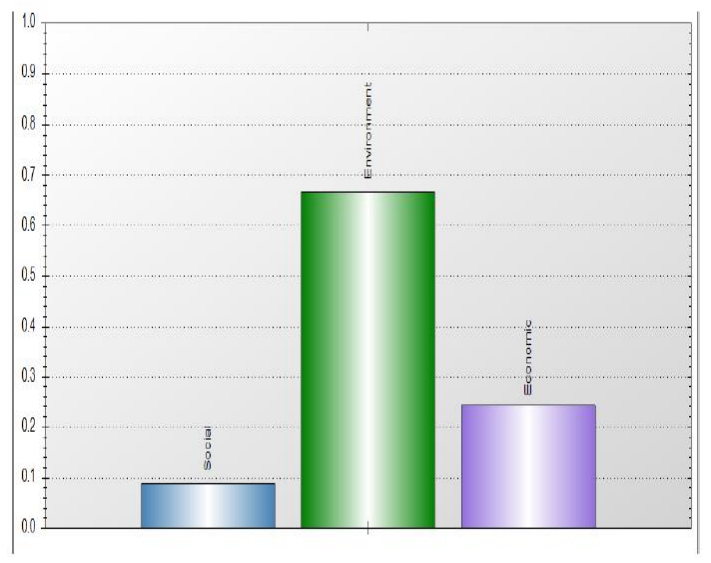

\begin{tabular}{|c|c|c|c|c|c|}
\hline Environment & Marine pro... & Forest ar... & Improved ... & $\mathbb{W}_{i}$ & \\
\hline Marine protected areas (... & 1.0000 & 0.1429 & 0.2000 & 0.0738 & \\
\hline Forest area ( $\mathrm{X}$ of land a... & 7.0000 & 1.0000 & 3. 0000 & 0.6434 & \\
\hline Improved water source, u... & 5.0000 & 0.3333 & 1.0000 & 0.2828 & \\
\hline Economic & Energy pro... & Foreign i... & Lending $x \ldots$ & Merchandise... & $\mathbb{W i}_{i}$ \\
\hline Energy production (kt of... & 1.0000 & 7. 0000 & 5.0000 & 0.5000 & 0.3358 \\
\hline Foreign investment inflows & 0.1429 & 1.0000 & 0.3333 & 0.1429 & 0.0508 \\
\hline Lending rate (percentage) & 0.2000 & 3.0000 & 1.0000 & 0.1429 & 0.0954 \\
\hline Merchandise trade (perce... & 2.0000 & 7.0000 & 7.0000 & 1.0000 & 0.5180 \\
\hline Social & Population... & Immunizat... & GDP per c... & Labor force... & $\psi_{i}$ \\
\hline Population growth (annua... & 1.0000 & 7. 0000 & 1.0000 & 3.0000 & 0.4214 \\
\hline Immunization, measles (X... & 0.1429 & 1.0000 & 0.2000 & 0.3333 & 0.0617 \\
\hline GDP per capita growth (a... & 1.0000 & 5.0000 & 1.0000 & 2.0000 & 0.3506 \\
\hline Labor force participatio... & 0.3333 & 3.0000 & 0.5000 & 1.0000 & 0.1663 \\
\hline
\end{tabular}

Figure 5. The weight figure of Rule layer
Figure 6. The weights figure of all affecting factor

\section{The Classification of Sustainable Level}

Based on models of the above sections, we develop a model for the sustainability of America. However, we do not have the specific data to provide a measure to distinguish more sustainable countries and policies from less sustainable ones. Thus, based on the two models at the front, we introduce the method of cluster analysis. According to cluster analysis, we analyze the sustainable level of the 14 countries in Table 1 . Here are the answers.

Based on Table 1, we gain four final center of cluster and divide the sustainable level into five parts, seeing in the Table 2. 
Table 1 Correlation Matrixes

\begin{tabular}{|c|c|c|c|c|c|}
\hline Country & America & France & $\ldots$ & China & Hungary \\
\hline labor force particip... & 63 & 56 & & 71 & 52 \\
\hline measles immunizat.. & 92 & 89 & & 99 & 99 \\
\hline per capita GDP & 51495.9 & 40908.3 & & 6092.8 & 12784.3 \\
\hline growth rate of popul... & 0.7 & 0.5 & & 0.5 & -0.5 \\
\hline$\ldots$ & & & & & \\
\hline lending rate & 3.3 & 1.6 & & 6 & 9 \\
\hline ?merchandise trade & 24 & 46.3 & & 45 & 156 \\
\hline marine conservat... & 30.4 & 58.5 & & 1.6 & 0 \\
\hline forestry area & 3047876 & 160500 & & 2123872.8 & 20474 \\
\hline water resources... & 98 & 100 & & 85 & 100 \\
\hline
\end{tabular}

Table 2 The classification of sustainable level

\begin{tabular}{|c|c|}
\hline L'range $\left(* 10^{7}\right)$ & level of sustainability rating \\
\hline$L<=1.466$ & Unsustainable development \\
\hline $1.466<L<=1.782$ & low level of sustainability \\
\hline $1.782<L<=7.742$ & middle level of sustainability \\
\hline $7.742<L<=8.918$ & good level of sustainability \\
\hline$L>8.918$ & very good level of sustainability \\
\hline
\end{tabular}

Obviously, based on the data gained by the cluster analysis in Table 2, we can make concrete distinction on the level of sustainable development. And we find that the level of the sustainable of several Developed and developing countries is at good sustainable degree or above, such as America, France, England and even China. However, the level of the country from the United Nations list of the 48 Least Developed Countries (LDC) list is at unsustainable degree. In addition, we distinguish more sustainable countries and policies from less sustainable ones successfully.

Based on Table 1, we gain four final center of cluster and divide the sustainable level into five parts, seeing in the Table 2.

Obviously, based on the data gained by the cluster analysis in Table 2, we can make concrete distinction on the level of sustainable development. And we find that the level of the sustainable of several Developed and developing countries is at good sustainable degree or above, such as America, France, England and even China. However, the level of the country from the United Nations list of the 48 Least Developed Countries (LDC) list is at unsustainable degree. In addition, we distinguish more sustainable countries and policies from less sustainable ones successfully.

\section{Conclusions}

The mathematical model and analysis on the sustainable development have been further studied in this paper. In order to assess countries with different degree of sustainable development, we adapt the Principal Component Analysis to collect a dozen factors which may affect the sustainable development for data analysis. We use the factor of principal component analysis to decide the solution layer of Analytic Hierarchy Process and the rule layer. Then we calculate level indicators of 14 countries with different degree of the sustainable development, and use these data for clustering analysis. At last, we get five clustering center. Therefore, according to the levels of these indicators and classification, we have distinguished more sustainable countries from less sustainable ones.

\section{Acknowledgments}

This work was partially supported by the Fundamental Research Funds for the Central Universities (N140504009), the Science Foundation of Ministry of Housing and Urban-Rural Development (grant no. K82016019), the Discipline HanYu Project of Shenyang Jinzhu University (grant no. XKHY-79) 
and the 9th group of education scientific research project topics of Shenyang Jianzhu University (grant no.20160124).

\section{References}

[1] D. S. Ambuj and N. Adil, The human development index: a critical review, Ecological economics. 25 (1998) 249-264.

[2] B. R. Adrian and S. V. AMERCO, Proposal and application of a Sustainable Development Index, Ecological Indicators. 2 (2002) 251-256.

[3] K. Devesh, The Common Pool Dilemma of Global Public Goods: Lessons from the World Bank's Net Income and Reserves, World Development. 30 (2002) 337-354.

[4] K. A. Stave, A system dynamics model to facilitate public understanding of water management options in Las Vegas Nevada, Environmental Management. 67 (2003) 303-313.

[5] E. O. Walsh, B. A. Pennoek and H. Shi, Quantitative Guidelines for Urban Sustainability, Technology in Society. 28(2006) 32-48.

[6] B. Ness, E. Urbel-Piirsalu and S. Anderberg, Categorizing tools for sustainability assessment, Ecological Economics. 60 (2007) 498-508.

[7] H.Y. Sun, Q.L. Zhang and N. Li, Synchronization of delayed complex dynamical networks via adaptive periodically intermittent control, Control and Decis. 28 (2013) 797-800.

[8] World Bank Data, http://data.worldbank.org.

[9] UN sustainable development knowledge platform, http://sustainabledevelopment.un.org

[10] International Institute for Sustainable Development, https://www.iisd.org/sd/ 